\title{
Experimental and Numerical Strength Analysis of Wagon for Transporting Bulk Material
}

\author{
Vladimir Milovanovic ${ }^{1, *}$, Miroslav Zivkovic ${ }^{1}$, Aleksandar Disic ${ }^{1}$, Dragan Rakic ${ }^{1}$, Jelena Zivkovic ${ }^{1}$ \\ ${ }^{1}$ University of Kragujevac, Faculty of Engineering
}

This paper presents comparative experimental and numerical strength analysis of wagon for transporting bulk material according to the TSI standard and norm EN 12663:2000. The aim of this analysis is to show that results of stresses obtained by measuring with strain gauges and stresses obtained by FEM calculation gives good agreement. Based on the results and their good match, it can be concluded that the numerical FEM analysis can be reliably used for structural analysis. According to this fact, FEM analysis can reduce number of the testing new products. This leads to great savings in the design of new prototypes, in order to immediately start the process of mass production. This would lead to significantly less cost of products.

Keywords: FEM, Wagon analysis, Fatigue strength analysis

\section{INTRODUCTION}

Numerical simulations are widely used for solving various problems in industry because they reduce time and cost in developing new products. Simulation results provide very useful information about the product and can indicate the potential problems that can be eliminated in design phase. The most powerful and widely used tool for numerical simulations is Finite element method (FEM).

The next step in projecting phase is making a prototype, based on the results obtained using FEM. When the prototype testing is finished, it is very important to make a comparative analysis of the results obtained by FEM calculation and by measurements on a prototype. Measurement results and results obtained by FEM calculation must meet all requirements for static and fatigue strength according to standards.

According to TSI standard [1] (Clause 4.2.2.3.1) and requirements from Clause 3, British Standard EN 12663:2000 [2], static and fatigue strength analysis of wagon for transporting bulk material are done. Measurement of stresses with strain gauges was done on a prototype, and those results were compared with stresses obtained by FEM calculation.

\section{FEM MODEL}

The mentioned wagon is designed for transporting bulk material which is resistant to the atmospheric influence. FEM model is created using the FEMAP software [3]. According to the construction type, shell elements of the appropriate thickness and 3D eight node elements (for modeling of support plate, compensating ring, traction stop) are used for creating the finite element mesh. The structure is modeled in details with 126380 elements and 125377 nodes. General element side length is about $40 \mathrm{~mm}$.

Different thicknesses of shell elements are presented with different colors. Figure 1 shows the 3D model of the whole wagon without bogies.

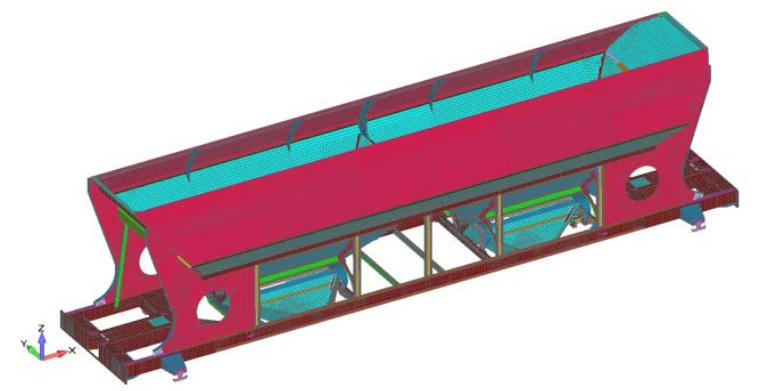

Fig. 1. Finite element mesh $-3 D$ vehicle model

Because of the correspodent symmetry only a quarter of the model will be used for the loaded cases, as shown in Figure 2. Full model of the wagon is used for unsymmetrical load cases and half of a model for analysing lifting of the wagon. Colors in Figures 1 and 2 match the various thicknesses of shell elements.

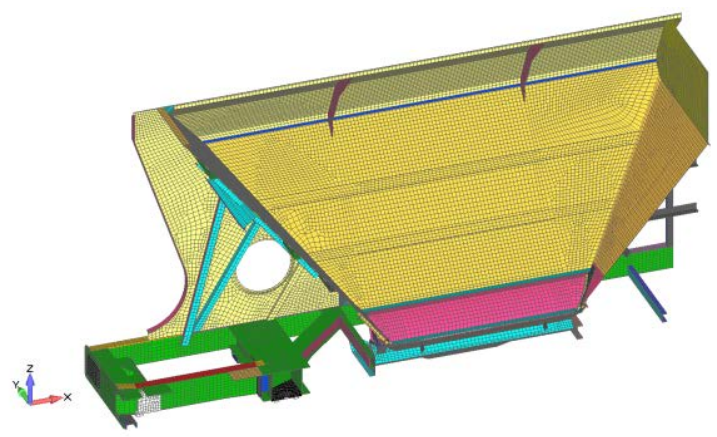

Fig. 2. Finite element mesh - quarter of 3D wagon model

\section{SAFETY FACTOR AND PERMISSIBLE STRESS}

According to EN 12663:2000, Clause 5.4, calculated permissible stress using Clause 3.4.2 is lower than calculated stress using Clause 3.4.3. Therefore, under the static load cases as defined in EN 12663:2000, Clauses 4.1 to 4.5 , the ratio of yield stress $\left(R=R_{e}\right)$ to calculated stress $\left(\sigma_{c}\right)$ must be greater than or equal to $S_{1}$, Table 1 . 
Table 1. Safety factor and permissible stress for static loads - parent material

\begin{tabular}{|c|c|c|}
\hline Material & Safety factor $S_{1}$ & $\sigma_{c \max }[\mathrm{MPa}]$ \\
\hline S355J2+N & 1.15 & 309 \\
\hline
\end{tabular}

According to Clause 3.4.2 of EN 12663:2000, safety factor $S_{1}$ may be taken as 1.0 for superposition of load cases.

Figure 3 shows pulsating stress in shape of the sinus function and also the idealized form of load. Fatigue load is used in the range of $\pm 30 \%$ of vertical static load. Based on this and Figure 3, we can calculate the value of the maximum stress at the fatigue load based on static analysis, [4]:

$\sigma_{\max }=2.1667 \Delta \sigma_{c}$

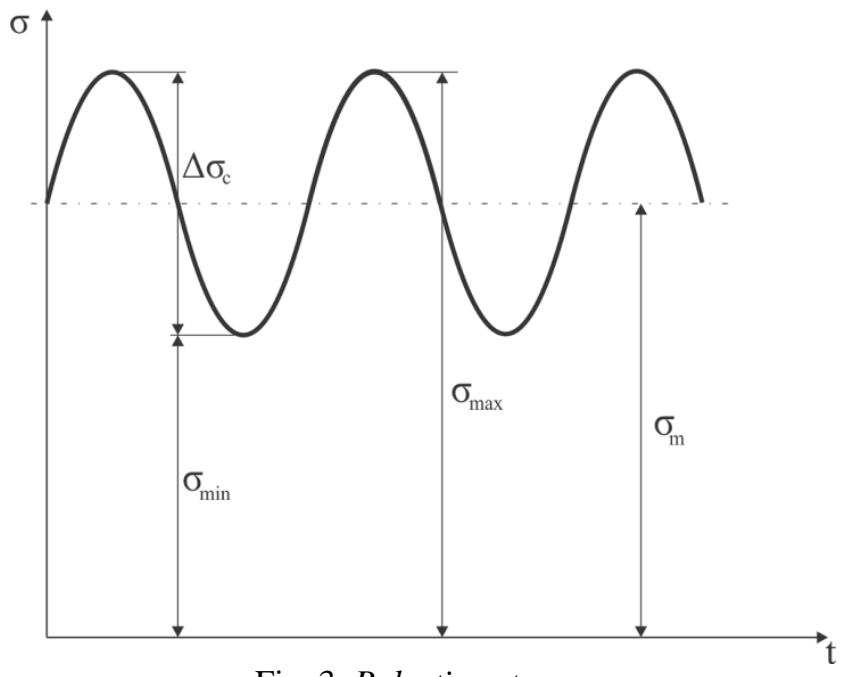

Fig. 3. Pulsating stress

Table 2 shows limit values for static test to verify fatigue strength in steel S355J2+N in accordance with Eurocode 3, Part 1.9 [5], using Figure 7.1 and table 3.1.

Table 2. Limit stress values for static test to verify fatigue strength in steel S355J2+N

\begin{tabular}{cccc}
\hline \multirow{2}{*}{$\begin{array}{c}\text { Direct stress range } \\
\Delta \sigma_{c}[\mathrm{MPa}]\end{array}$} & $\begin{array}{c}\text { Permissible maximum } \\
\text { fatigue stress } \sigma_{\text {max lim }} \\
{[\mathrm{MPa}]}\end{array}$ & $\begin{array}{c}\text { Low consequence } \\
\left(\gamma_{\text {Mf }}=1.15\right)\end{array}$ & $\begin{array}{c}\text { High consequence } \\
\left(\gamma_{\text {Mf }}=1.35\right)\end{array}$ \\
\hline 160 & 347 & 301 & 257 \\
\hline 100 & 217 & 188 & 160 \\
\hline 90 & 195 & 170 & 144 \\
\hline 80 & 173 & 151 & 128 \\
\hline 71 & 154 & 134 & 114 \\
\hline 63 & 136 & 119 & 101 \\
\hline 56 & 121 & 106 & 90 \\
\hline 50 & 108 & 94 & 80 \\
\hline
\end{tabular}

Figure 4 and Equations (2) and (3) show the way of determining the size of the weld zone for FEM analysis.

$$
\begin{aligned}
& D_{1}=f_{\text {ele }}\left(0.5 t_{\text {neighbor }}+t_{\text {min }}\right)=1 \cdot\left(0.5 t_{2}+t_{2}\right) \\
& D_{2}=f_{\text {ele }}\left(0.5 t_{\text {neighbor }}+t_{\text {min }}\right)=1 \cdot\left(0.5 t_{1}+t_{2}\right)
\end{aligned}
$$

Figure 5 shows appropriate finite element model of welded joints and stresses.

$\sigma_{w f}=\sqrt{\sigma_{\perp f}^{2}+\tau_{\perp f}^{2}}$

$\sigma_{w f}$ is the equivalent stress,

$\sigma_{\perp f}$ is the normal stress,

$\tau_{\perp f}$ is the shear stress.

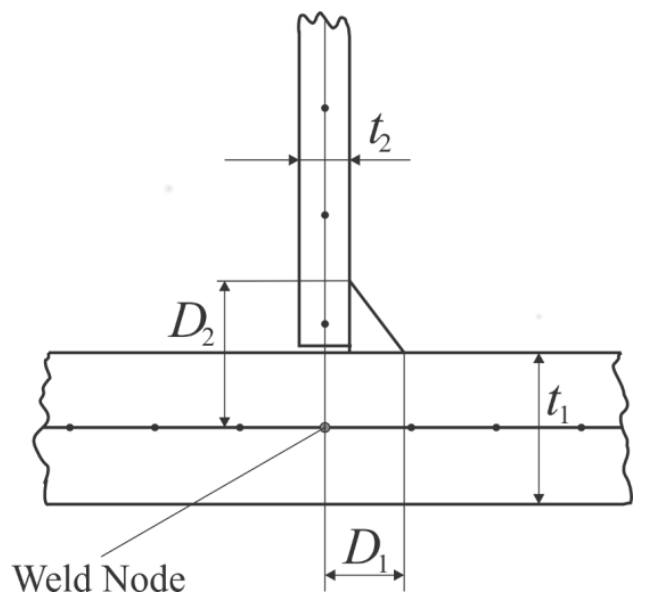

Fig. 4. Size of the weld zone for FEM calculation 


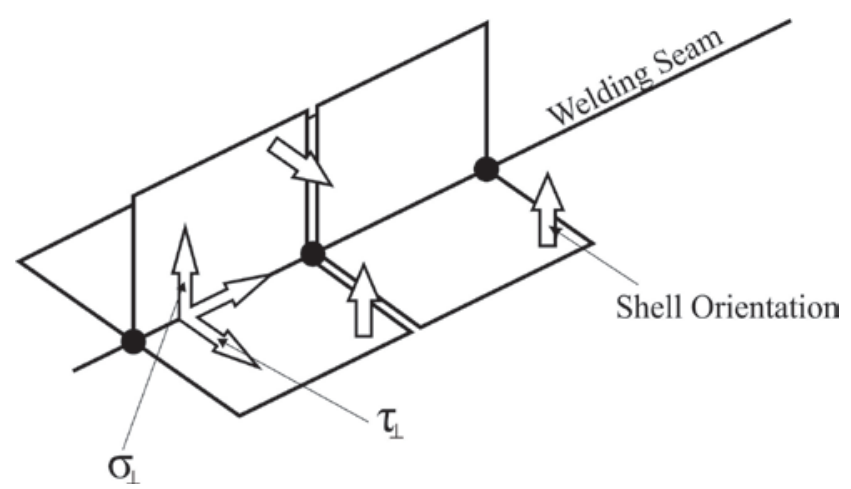

Fig. 5. Proper orientation of the shell element in the weld zone

\section{LOAD CASES AND REQUIREMENTS}

According to TSI [1], Clause 4.2.2.3.1, wagon structure is necessary to calculate in relation to different types of load:

- Exceptional loads, which cover: longitudinal design loads, maximum vertical load, load combinations, lifting and jacking and other exceptional loads;

- $\quad$ Service (fatigue) loads.

Exceptional load cases are specified in TSI [1], Clause 4.2.2.3.2 and EN 12663:2000 [2]. For all exceptional load cases maximum value of calculated stress must be lower than the permissible stress shown in the Table 1.

Service (fatigue) loads are specified in TSI [1], Clause 4.2.2.3.3 and EN 12663:2000 [2], Clause 4.6, 5.2, Table 15 Acceleration in y-direction and Clause 4.6, 5.2, Table 16 Acceleration in z-direction. Limit values for static test to verify fatigue strength, which are determined for minimum number of 2 million constant amplitude cycles, using Eurocode 3, are given in Table 2.

For service (fatigue) loads maximum value of calculated stress in welded joints must be lower than the limit stress for safe life in the Table 2.

\section{MEASURING AND POSITION OF STRAIN GAUGES}

According to the results obtained by FEM calculations for all of the load cases defined in accordance with TSI standard and with British Standard EN12663:2000, strain gauges were set up on prototype of the wagon and measurements were carried out. Strain gauges showed the results of stresses at those locations.

Position of strain gauges is selected so that it covers all the places on the wagon where the numerical calculations showed the stress concentration. Schematic view of the position of strain gauges is shown in Figure 6.

\section{COMPARATIVE RESULTS OF STRESSES}

The values of stresses at the locations of strain gauges were obtained for all cases of static loads and static test for verification of fatigue strength. The measured values of stresses at the locations of strain gauges and the values of stresses obtained from the FEM calculations, using software PAK [6], were compared.

The aim of the analysis was to show that the results obtained by measurement and calculations based on FEM gave similar values of stress, bellow the values of permissible stress defined according to TSI and EN 12663:2000.

Maximal measured stress of $322 \mathrm{MPa}$ is at the place of strain gauge 158, and it was measured for longitudinal case of load, when compressive force acted at coupler level; $\mathrm{F}=2000 \mathrm{kN}$.

Stresses shown in report obtained by measuring with strain gauges actually are normal stresses in direction of strain gauge.

Places of strain gauge 158, as strain gauges 157 and 159 are shown in Figure 7a). Results obtained by FEM analysis are shown in Figure 7b).

In the Table 3 are shown comparative results obtained by strain gauges and appropriate normal stresses obtained by FEM analysis.

Difference between results obtained by strain gauges and FEM analysis is lower than 5\% which is acceptable. It can be observed that stress is higher than $309 \mathrm{MPa}$ and that does not meet safety factor 1.15. It should be noted that stress $332 \mathrm{MPa}$ is lower than $\mathrm{R}_{\mathrm{e}}=355 \mathrm{MPa}$ for material S355J2+N. According to BS EN $12663: 2000$, Clause 3.4.2, $S_{1}$ may be taken as 1.0 where the design load cases are to be verified by test.

For the load case of maximal vertical load at positions 151, 153, 165 and 231, comparative results obtained by strain gauges and appropriate normal stress obtained by FEM analysis are given in the Table 4 .
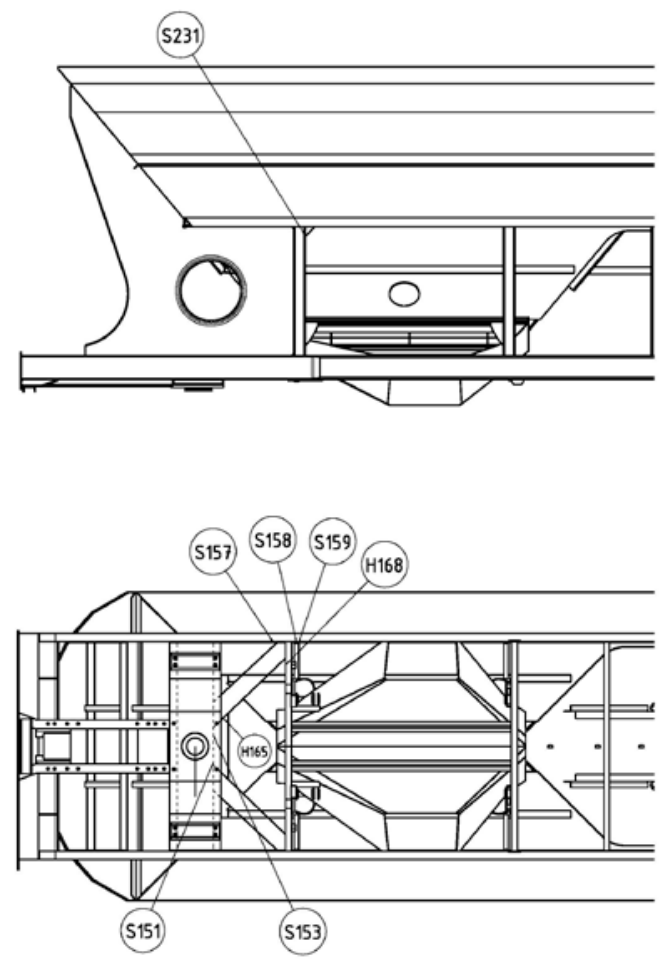

Fig. 6. Position of strain gauges 

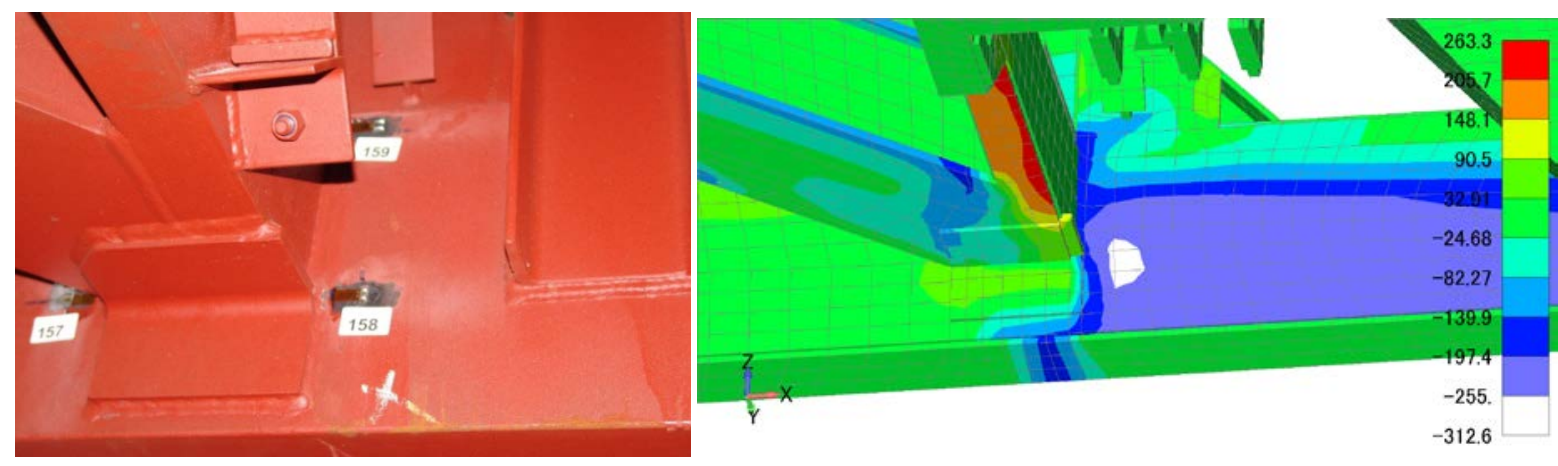

Fig. 7. a) Strain gauges 157, 158 and 159; b) X Normal stress field

Table 3. Comparative results obtained by strain gauges and FEM analysis for longitudinal case of load when compressive force acting at coupler level; $F=2000 \mathrm{kN}$

\begin{tabular}{|c|c|c|c|c|c|}
\hline \multirow{2}{*}{$\begin{array}{l}\text { Strain gauge } \\
\text { number }\end{array}$} & \multicolumn{2}{|c|}{ Stress $\sigma_{x x}[\mathrm{MPa}]$} & \multirow{2}{*}{$\begin{array}{c}\text { Difference in } \\
\%\end{array}$} & \multicolumn{2}{|c|}{ Figure number } \\
\hline & Strain gauge & $\begin{array}{c}\text { FEM } \\
\text { analysis }\end{array}$ & & Strain gauge & FEM analysis \\
\hline 157 & -31 & -30.9 & 0.3 & \multirow{3}{*}{ 7a) } & \multirow{3}{*}{ 7b) } \\
\hline 158 & -322 & -312.6 & 2.9 & & \\
\hline 159 & -248 & -258.7 & 4.1 & & \\
\hline
\end{tabular}
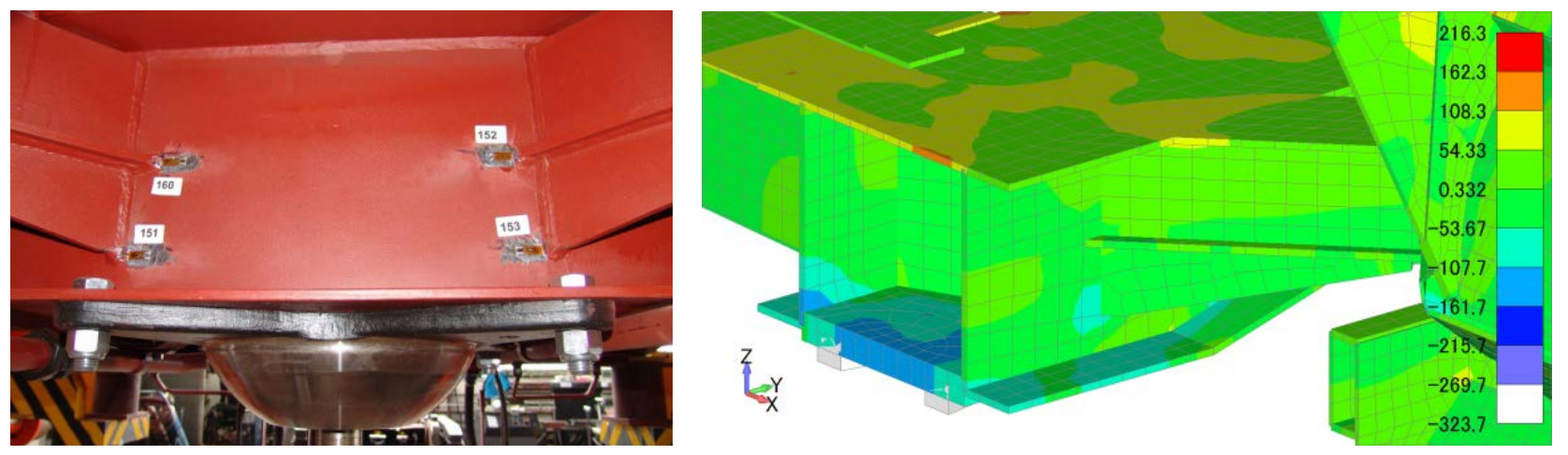

Fig. 8. a) Strain gauges 151 and 153; b) Y Normal stress field
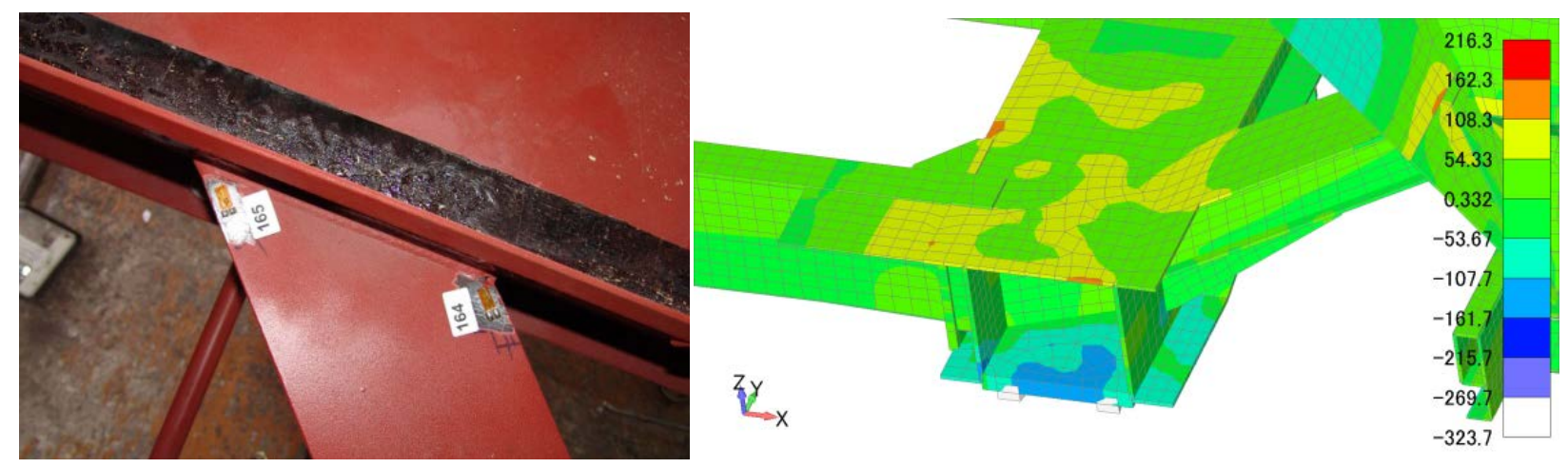

Fig. 9. a) Strain gauges 164 and 165; b) Y Normal stress field 

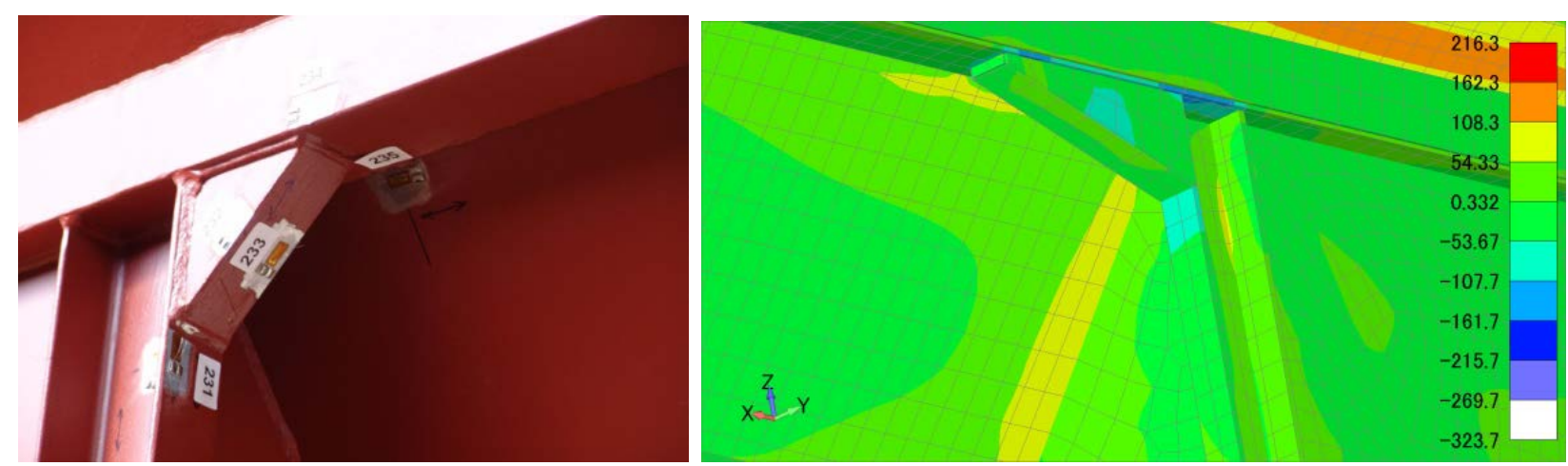

Fig. 10. a) Strain gauge 231, 233 and 235; b) Y Normal stress field
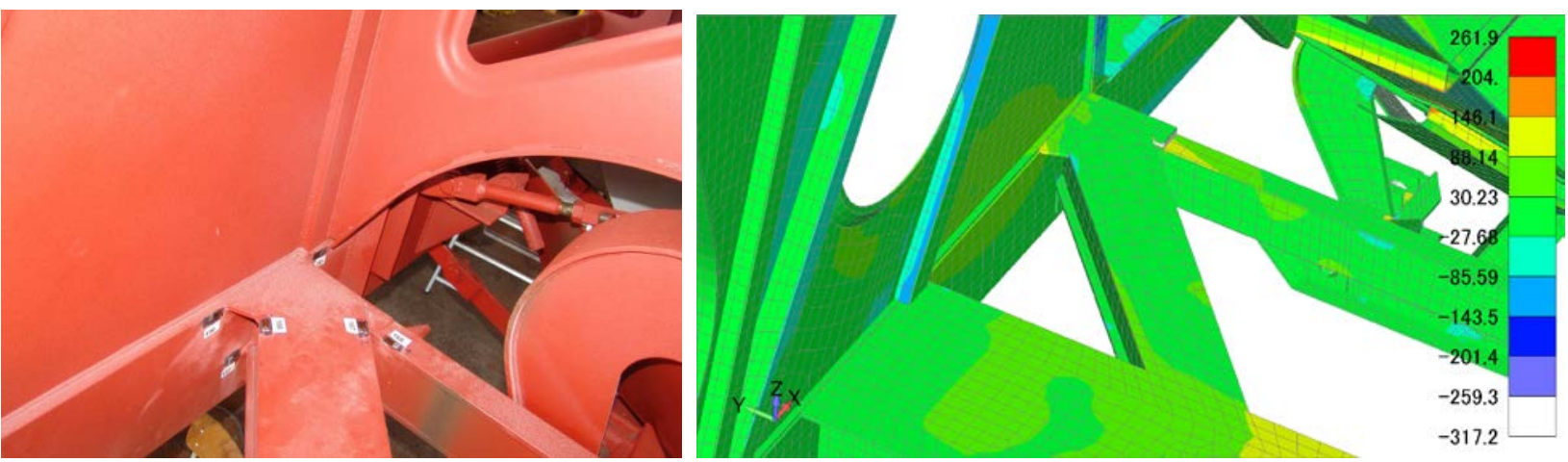

Fig. 11. a) Strain gauge 166, 167 and 168; b) X Normal stress field

Table 4. Comparative results obtained by strain gauges and FEM analysis for longitudinal case of load when compressive force acting at coupler level; $F=2000 \mathrm{kN}$

\begin{tabular}{ccccccc}
\hline \multirow{2}{*}{$\begin{array}{c}\text { Strain gauge } \\
\text { number }\end{array}$} & \multicolumn{2}{c}{ Stress [MPa] } & Difference in & \multicolumn{2}{c}{ Figure number } \\
\cline { 2 - 3 } & Strain gauge & $\begin{array}{c}\text { FEM } \\
\text { analysis }\end{array}$ & & & Strain gauge & FEM analysis \\
\hline 151 & -126 & -121.7 & 3.4 & & 8a & 8b \\
\hline 153 & -127 & -121.7 & 4.2 & & $9 \mathrm{~b}$ \\
\hline 165 & 114 & 106 & 7 & & $9 \mathrm{a}$ & 9 \\
\hline 231 & -122 & -116 & 4.9 & & $10 \mathrm{a}$ & $10 \mathrm{~b}$ \\
\hline 168 & 112 & 125 & 10 & & $11 \mathrm{a}$ & $11 \mathrm{~b}$ \\
\hline
\end{tabular}

\section{FATIGUE LOADS - CALCULATION RESULTS}

For the most conventional wagon designs, the loading defined in Table 16 of EN12663 is considered as sufficient to represent the full effective combination of fatigue load cycles. Source of fatigue loading is determined according to TSI, Annex CC. The fatigue load used in design is in range of $\pm 30 \%$ of vertical static load, figure 3.

According to Clause 5.2 of EN12663, the behavior of materials under fatigue loading is based on Eurocode 3, part 1.9 as well as TSI, Annex N.

Based on the results obtained by analyzing the static strength of the wagon and considering the good match of results obtained by experiment and by FEM analysis, it can be concluded that the fatigue strength of the wagon can be checked using the results of the static test, Table 2.

In assessment of the permissible stresses for fatigue strength it is necessary to observe underframe of the wagon and wagon box separately.

Safety factors are taken from the Eurocode 3 and shown in Table 2 of this paper, where the safety factor for the underframe is 1.35 and for wagon box is 1.15.

Figure 12a shows significant loaded zone in underframe, and figure 12b shows significan loaded zone in wagon box assembly.

Stress levels used in the legend in figures 12 and 13 are defined according to Table 2 . 

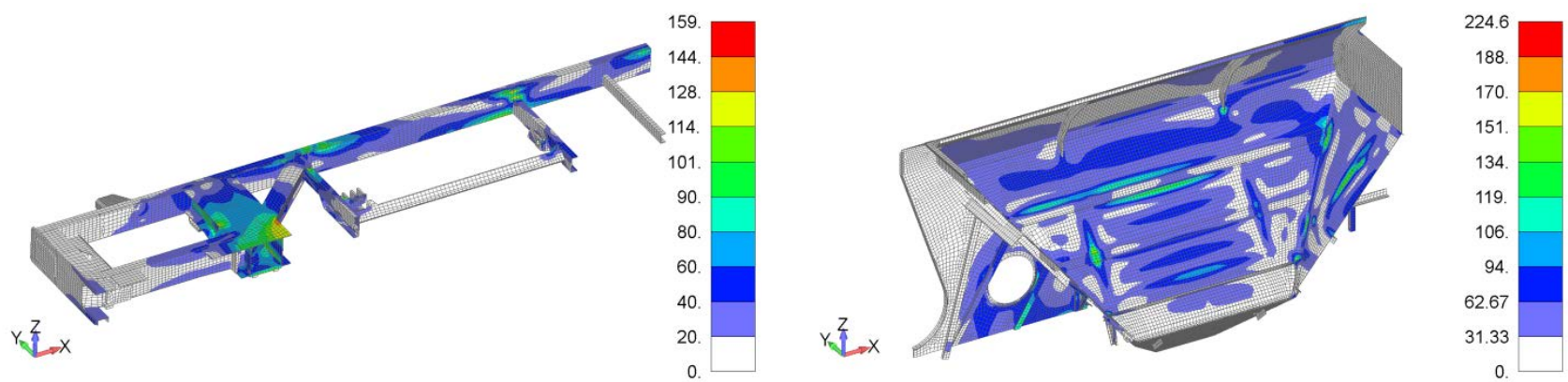

Fig. 12. Von Mises equivalent stress field a) underframe; b) wagon box
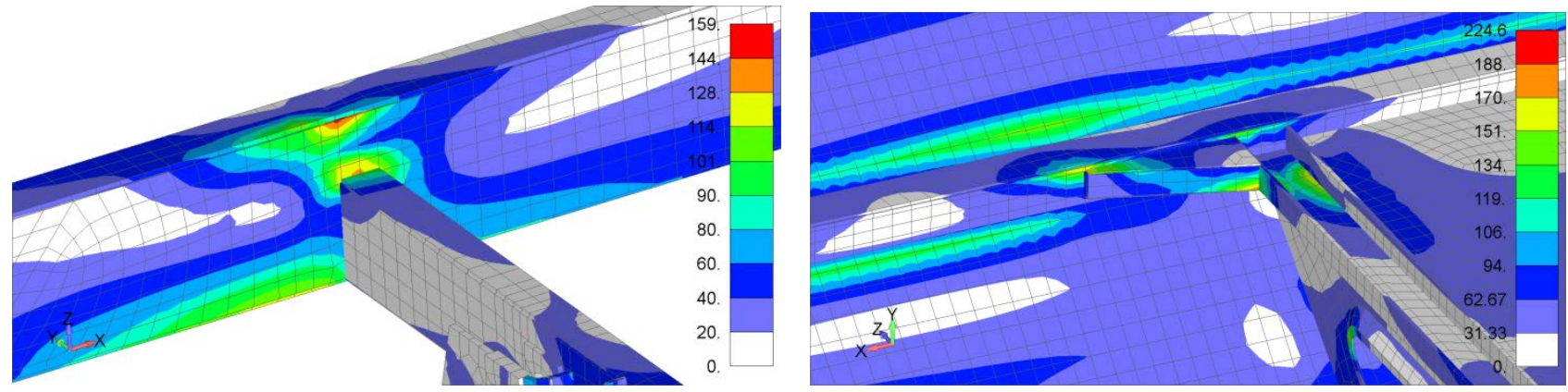

Fig. 13. Maximal Von Mises equivalent stress - significant loaded zone a) underframe; b) wagon box

A review of types of welds in accordance with the Eurocode-3, Section 1.9 and based on the documentation on the technology of welding, welded joints (Figures 13) belong into the category 100 type of welds. This type of weld is given in the Eurocode-3, Section 1.9 in Table 8.2, constructional detail 6. According to Table 2 for detail category 100 of butt weld, the welds limit stress for safe life is $160 \mathrm{MPa}$ (underframe) and $188 \mathrm{MPa}$ (wagon box). According to calculation results at the place of weld, Figure 13a, stress is $158 \mathrm{MPa}$, which is below than permissible maximum fatigue stress in Table 1. According to calculation results at the place of weld, Figure. 13b, stress is $181 \mathrm{MPa}$, which is below than permissible maximum fatigue stress in Table 2.

Based on calculated stresses and limit stresses given in Table 2, it can be concluded that all calculated stresses in the parent material and welded joints are below limit stress for safe life for appropriate weld type.

\section{CONCLUSIONS}

The aim of this paper was to compare results of stresses obtained by measuring with strain gauges and stresses obtained by FEM calculation. This analysis demonstrates applying of the most common European standards for calculating static and fatigue strength of wagon. Comparing the numerical results with the results of measuring, it is verified that software gives good agreement with the experimental results. Difference between results obtained by strain gauges and FEM analysis is lower than $10 \%$. According to presented results it can be concluded that FEM analysis can reduce number of the testing new products. This would lead to big savings and significantly less cost of products.

\section{ACKNOWLEDGEMENT}

The part of this research is supported by Ministry of Education, Science and Technological Development, Republic of Serbia, Grant TR32036.

\section{REFERENCES}

[1] TSI Standard - Freight wagons of the trans-European conventional rail system

[2] EN 12663:2000 - Railway applications - Structural requirements of railway vehicle bodies, European Standard

[3] FEMAP Version 10, User Guide, Siemens Product Lifecycle Management Software Inc, Munich Germany, 2009

[4] Milovanović, V., Dunić, V., Rakić, D., Živković, M., Identification causes of cracking on the underframe of wagon for containers transportation - Fatigue strength assessment of wagon welded joints, Engineering Failure Analysis, Vol.31, pp. 118-131, ISSN 13506307, 2013

[5] Eurocode 3: Design of steel structures - Part 1.9: Fatigue

[6] Živković, M., Kojić, M., Slavković, R., Grujović, N., PAK-S Program for FE structural analysis, Faculty of Mechanical Engineering, University of Kragujevac, Serbia, 2003 